\title{
Por entre as linhas: imaginário, saberes e fazeres docente
}

Jordelina Beatriz Anacleto Voos ${ }^{a}$

\section{Editores}

Maria Inês Côrte Vitoria PUCRS, Brasil

Pricila Kohls dos Santos PUCRS, Brasil

\section{Equipe Editorial}

Carla Spagnolo PUCRS, RS, Brasil

Marcelo Oliveira da Silva PUCRS, RS, Brasil

Rosa Maria Rigo

PUCRS, RS, Brasil

\section{ISSN 2179-8435}

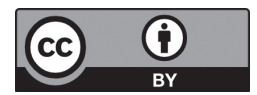

A matéria publicada neste periódico é licenciada sob forma de uma Licença Creative Commons - Atribuição 4.0 Internacional. http://creativecommons.org/licenses/by/4.0/
RESUMO: Este artigo trata de uma experiência, na prática de pesquisa em educação sobre o exercício de reflexão de um professor de educação física, referente à sua prática, mediante o registro de atividades. À luz dos procedimentos da Análise de Conteúdo, referencial construído por Bardin (2002), foram analisados os textos de oito diários de classe. Emergiram muitos elementos sobre a prática do professor, dentre eles, destacou-se o significado do espaço físico escolar e a relação, desse espaço, com os saberes e fazeres docentes, trazidos pelo seu autor. Ao analisar os textos dos diários, isto é, apreender, pela e na narração, o que o professor pensa, sente, sabe e faz, enquanto profissional, incorpora-se à interlocução a produção de texto fundamentador, como possibilidade de traduzir, teoricamente, os posicionamentos do pesquisado, produtores de sentido, implícitos e/ ou explícitos na reflexão. Esse exercício, realizado (análise, interpretação e interlocução mediadas, pela devida fundamentação teórica) constituiu o processo de investigação.

Palavras-chave: Educação Física. Prática pedagógica. Diários de classe.

ABSTRACT: This article discusses an experiment in the practice of education research about an exercise of reflection by a physical education teacher concerning his own practice, based on his activity records. Focuses on procedures of content analysis, benchmark built by Bardin (2002), texts of eight class diaries were analyzed. Many elements have emerged on this teacher practice, among them, the meaning of physical space and its relationship with the teachers' knowledge and practices brought by his author. Analyzing the texts of the class diaries, that is, apprehend, by and in the narration, what the teacher thinks, feels, does and knows as a professional, joins the dialogue to grounding text production, as a possibility to translate theoretically the researched points of view, producers of meaning, implicit and/or explicit in the reflection. This exercise, conducted (analysis, interpretation and mediated dialogue, by proper theory) constituted the research process.

Keywords: Physical Education. Pedagogical practice. Class diaries.

a Possui graduação em Pedagogia pela Faculdade de Educação de Joinville (1976), mestrado em Educação pela Pontifícia Universidade Católica do Rio Grande do Sul (1989) e doutorado em Engenharia de Produção pela Universidade Federal de Santa Catarina (2004). Concluiu estudos de Pós-doutorado na Universidade de Atacama (UDA) - Chile (2009). É professora do quadro de carreira da Universidade da Região de Joinville. <jordelina.voos@acad.pucrs.br>. 
abalza (2004) desafia os educadores ao exercício de reflexão sobre a sua prática pedagógica, mediante o registro das atividades, como docentes. Esse exercício de escrever sobre a prática, com determinada periodicidade, o autor em cena denomina de diários de classe.

Desta forma os diários tornam-se excelente material para avaliar o desempenho do professor e, consequentemente, avaliar o processo de ensinagem ${ }^{1}$. Constituem-se, também, em rico material para a pesquisa em educação, em especial sobre a prática pedagógica, quando disponibilizados para os pesquisadores que, em conjunto com os autores dos diários, procedem à análise em busca de dados, pistas e outros achados desveladores daquela prática.

Foi à luz desse entendimento que nasceu a proposta de investigar os saberes e fazeres docentes a partir dos textos dos diários de aula escritos por um professor de educação física.

No diálogo com o escrito, emergiram, por entre as linhas dos textos dos diários, muitos elementos que poderiam propiciar a investigação sobre a prática do professor. Dentre eles destacou-se o significado do espaço físico escolar e a relação com os saberes e fazeres docentes, trazidos pelo seu autor.

E o que se pretende, neste relato, é descrever os resultados da pesquisa, a partir dos textos dos diários de classe, sobre o significado do espaço físico escolar para o professor de educação física e a relação, desse espaço, com o seu exercício de docência.

Para dar conta da tarefa, os textos dos diários foram analisados com base no referencial construído por Bardin (2002), na tentativa de encontrar expressões e/ou unidades de sentido desveladoras do significado do espaço físico escolar, para o professor, que indicassem as relações possíveis entre espaço e prática pedagógica e, a partir dos achados ${ }^{2}$, aprofundar a reflexão sobre a prática pedagógica do professor de educação física.

Tendo como fio condutor a questão que focava o significado espaço físico, para o professor de educação física investigado, como um indicador de qualidade para a sua prática pedagógica, os textos dos diários foram desmembrados em unidades de sentido (seleção de eventos) ${ }^{3}$ e, posteriormente, as unidades foram reagrupadas em categorias de análise.

Desse modo a composição do texto fundamentador, que dá suporte à interpretação dos diários, sustenta-se nas categorias organizadas em três conjuntos assim constituídos: imaginário e espaço; espaço e prática pedagógica; saberes e fazeres do professor de educação física.

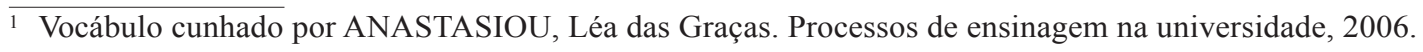

2 Achados significam os dados a que o pesquisador atribui significativa relevância para a investigação.

3 Termo apresentado por Zabalza para designar as descrições que são relevantes para o professor.
} 
Cabe destacar que todo o processo investigativo orientou-se pela abordagem da pesquisa qualitativa, na ótica de Minayo (2004) por se tratar de material autobiográfico. Caracteriza-se como um estudo de caso, na perspectiva de que o documento (diários de classe) é revelador da dinâmica da atividade de apenas um sujeito.

Segundo Hernández (1985), o estudo dos documentos pessoais possibilita a interlocução entre a vivência pessoal e o contexto social. No caso específico, o sujeito estudado é representativo entre o grupo de educadores. Essa corrente metodológica tem sido expressiva, na pesquisa educacional, na medida em que a pesquisa sobre a vida dos professores incide sobre a sua prática pedagógica.

Assim, os diários de classe constituem um recorte de determinados elementos cujos textos ganham efeito e as palavras produzem sentidos e significados, como explica Larrosa (2002, p. 20):

as palavras produzem sentido, criam realidade e [...] funcionam como potentes mecanismos de subjetivação. Eu creio no poder das palavras, na força das palavras, creio que fazemos coisas com as palavras e, também, que as palavras fazem coisas conosco.

O fato de analisar os textos dos diários, isto é, apreender, pela e na narração, o que o professor pensa, sente, sabe e faz, enquanto profissional, assim como as razões que o levaram a agir dessa ou daquela maneira, incorporase à interlocução a produção do texto fundamentador, como possibilidade de traduzir, teoricamente, os posicionamentos do pesquisado, produtores de sentido, implícitos e/ou explícitos na reflexão. Esse exercício, realizado (análise, interpretação e interlocução mediadas, pela devida fundamentação teórica) constituiu o processo de investigação.

\section{O processo de interlocução mediada: o diálogo com o escrito}

\section{Imaginário e espaço}

Com o desenvolvimento de habilidades superiores, a relação que se institui entre o humano e a realidade não é direta. A relação é mediada por processos de pensamento, o que significa dizer que não necessitamos tratar das coisas diretamente, mas sim com os significados a elas atribuídos pela cultura. A produção cultural dos grupos humanos é repleta de alegorias ou símbolos resultantes da extensão concreta do imaginário. Assim, o imaginário é fundante do pensamento, é instituinte do sentido e, também, é instituinte do sujeito e do seu coletivo.

Castoriadis (1982, p. 154) afirma que o "imaginário utiliza o simbólico para exprimir-se e para existir, ao mesmo tempo em que o simbolismo pressupõe a capacidade imaginária, a capacidade de investir significações”. À luz desse 
entendimento, um representa o outro, fornecendo respostas a perguntas colocadas implicitamente pelo próprio fazer social. O imaginário se traduz na habilidade de criação/recriação própria do ser humano e como capacidade para a representação do mundo.

Na visão de Durand (1997) o importante é entender que esse movimento caracteriza-se pela função mediadora das relações que o homem estabelece consigo mesmo, com o outro e com tudo o que está ao seu redor. O símbolo é representação, não uma substituição. Por isso é próprio do símbolo permanecer indefinidamente sugestivo, tornando possível a cada sujeito ver o que a sua percepção lhe permite.

É pela educação, como processo de mediação, que a escola desempenha um importante papel, proporcionando ao sujeito as formas de encontrar sentido na significação social e nas criações sociais que constituem o imaginário da sociedade, as formas de representação ${ }^{4}$ e apropriação, os diferentes tipos de sujeitos, em função das relações sociais, econômicas e culturais que interferem nos processos educativos, regulando-os, no dizer de Severino (1992, p. 13): "de um lado a sociedade precisa da ação dos educadores para a concretização de seus fins, de outro os educadores precisam do dimensionamento político do projeto social para que sua ação tenha real significação enquanto mediação". Essa relação fica explicita em lugares e espaços de produção de discursos pedagógicos.

Segundo Chartier (1990), os discursos apreendem e estruturam o real, expressam determinada leitura de mundo em um dado lugar. E é a partir da compreensão dessa expressividade que se exercitam as práticas culturais, produtoras de símbolos, o presente adquire sentido, o outro se torna inteligível e o espaço decifrável.

Conforme Horn (2004), o espaço não é algo dado naturalmente, mas sim construído. Vale ressaltar a concepção de espaço e de ambiente. A autora, citada acima, deixa claro que o espaço refere-se ao espaço físico, aos locais onde as atividades são realizadas, e o ambiente refere-se ao conjunto desse espaço físico e às relações que nele se estabelecem. É o todo, indissociável: pessoas, objetos, formas, sons, cores, odores... Nas dimensões física, funcional, temporal e relacional, o espaço contém tudo e ao mesmo tempo é contido pelos elementos que lhe dão vida, sentido, condições e possibilidades. O espaço fala! Acolhe, rejeita, estimula, inibe, inquieta, tranquiliza...

\footnotetext{
$\overline{4}$ A teoria das representações sociais é obra do francês Serge Moscovici (1961) com grande destaque na compreensão das formas de produção de saberes e fazeres em diversos campos de conhecimento, que se manifestam como elementos cognitivos: imagens, conceitos, teorias... Mas que não se reduzem apenas aos componentes cognitivos. Essas formas são socialmente elaboradas e compartilhadas e devem ser entendidas a partir do seu contexto de produção. "As representações compreendem um conjunto de conceitos, afirmações e explicações pelas quais se procede à interpretação e mesmo à construção das realidades” (MOSCOVICI, 1984 apud SÁ, 1995).
} 
Nesse caso o espaço, palco da experiência humana objeto de estudo, é o espaço físico escolar que, pelas suas características, legitima-se como um elemento curricular. Entretanto, são pouco frequentes as referências explícitas sobre a sua constituição, o uso que dele se faz e as implicações pedagógicas decorrentes.

Neste sentido, os espaços construídos e/ou criados nas instituições educativas, não são neutros, cumprem uma finalidade, demarcando no ambiente os significados e os sentidos das relações que aí se estabelecem. Nos textos dos diários em análise fica evidente a posição que a disciplina Educação Física ocupa no ambiente escolar, a atribuição do seu significado no currículo, incluindo evidentemente o espaço do próprio corpo e o sentido da criação de hábitos, regras, rituais e tradições, muito próprios da cultura escolar. Está explícito que, para o professor pesquisado, usufruir do espaço físico para as práticas corporais qualifica o seu fazer pedagógico, o que representa uma fonte de saberes e fazeres. Porém esse, em que habita, constitui um foco de tensões e frustrações, em se tratando das situações de ensino/aprendizagem, conforme declara.

Além do espaço acanhado da sala [...] tive desentendimento com as duas turmas. As crianças ficaram inquietas e descontentes e começaram a se agredir. Tenho que dividir espaços. O professor das séries finais ocupa a quadra [...] tenho alunos menores [...]. (Recorte do texto do diário do professor de 23/03/2009.)

Tais elementos do recorte trazem, além da percepção do educador sobre os traços da construção de seu imaginário pedagógico referente à dimensão física do espaço, suporte e itinerário do exercício da docência, as críticas sobre as relações de coexistência e como as tais vão-se produzindo historicamente e são praticadas na instituição escolar. Infere-se, também o lugar atribuído aos saberes e os espaços dos professores e o privilégio de certas práticas corporais.

[...] a instituição escolar ocupa um espaço que se torna, por isso, lugar. Um lugar específico, com características determinadas, aonde se vai, onde se permanece umas certas horas de certos dias, e de onde se vem. Ao mesmo tempo, essa ocupação de espaço e sua conversão em lugar escolar leva consigo sua vivência como território por aqueles que com ele se relacionam. Desse modo é que surge, a partir de uma noção objetiva - a de espaço - lugar - uma noção subjetiva, uma vivência individual ou grupal, a de espaço - território. (VIÑAO, 2005, p. 17)

O espaço escolar enquanto território explica as relações com outros espaços ao seu redor, aponta a sua distribuição e o seu uso, a hierarquia de sua ocupação, haja vista a determinação de quem detém o poder. Mas é no plano do imaginário que essas inferências são gestadas, antecedendo sua própria materialização. 
Foucault (1987) discute o controle e a disciplina dos corpos, a partir da planificação das escolas, no sentido da adaptação e Certeau (1994) alerta para as maneiras de fazer, para as formas de apropriação do espaço. Nas pesquisas de Vago (2002), sobre a constituição da cultura escolar, consta que para cumprir os programas das disciplinas, nos projetos arquitetônicos dos grupos escolares, foi previsto galpões que deveriam ser cobertos e cimentados, ou seja, a construção de espaços específicos para os exercícios físicos. Esse dado permite inferir que uma cultura em torno das práticas corporais foi-se construindo historicamente. Essa cultura, apropriada pelo professor, consequentemente, tem o espaço como elemento imprescindível para a sua configuração.

Para minha alegria $[\ldots]$ as séries finais tiveram período reduzido e eu pude usar a quadra maior. (Recorte do diário do dia 23/03/2009.)

Deve ser assinalado que, na descrição, há um duplo sentido. Primeiro, a denúncia do espaço negado, em virtude da hierarquia para a ocupação, evidenciando que ao professor dos alunos maiores é dado o privilégio de utilização de uma quadra, cujo espaço é significativo para as práticas corporais, remetendo ao imaginário das práticas sociais. Em uma sociedade desigual, o espaço será desigualmente ocupado, distribuído e significado. Segundo, no prazer informado, o anúncio da apropriação do território, embora de forma clandestina ${ }^{5}$, por não ser uma conduta habitual. Mas esse território lhe pertence mesmo que, na planificação da gestão da escola, o espaço não lhe esteja destinado. O território, no imaginário do professor, está igualmente, presente em toda a espacialidade.

Em se tratando de uma situação de ensino, no posicionamento desse professor, explicitamente, se estabelece a relação espaço e qualidade da prática pedagógica e, entre linhas, que o saber docente é um saber, cujos componentes são hierarquizados em função do valor que lhes é atribuído e da sua utilidade percebida, podendo constituir, no espaço escolar, comunidades epistemológicas distintas.

Outra particularidade diz respeito à relação hierarquia e grau de escolaridade. Para os alunos pequenos, espaços pequenos. A instituição negligencia, assim, as necessidades e as especificidades da infância e do seu agir corporal, aspectos imprescindíveis para o desenvolvimento e a aprendizagem. E, na mesma ordem, volta à tona a questão: a relação do espaço com a qualidade da prática pedagógica. Porém, não há indicativo, nos escritos, quanto aos saberes e fazeres para qualificar esta prática.

\footnotetext{
$\overline{5}$ A utilização do termo refere-se à atitude deliberada do professor em apropriar-se de um espaço que não havia sido destinado às suas aulas.
} 


\section{Espaço e prática pedagógica}

Rodrigues (2003) apresenta um estudo que trata da relação entre a expansão do ensino público no Brasil e a estrutura física das unidades escolares entre 1920 e 1980. Para o autor, o prédio escolar é analisado como um problema social a ser solucionado no campo das políticas públicas. Em face da demanda, as unidades escolares foram construídas em áreas impróprias, com espaços físicos inadequados e ambientes dispostos de forma irracional. $\mathrm{Na}$ avaliação de Souza Lima (1998, p. 31) a qualidade das instalações escolares afeta diretamente o desenvolvimento do currículo e, como consequência, o processo de ensino e de aprendizagem: "o espaço físico é material riquíssimo e está sendo totalmente desprezado. Nos projetos de construções escolares não há lugar para bibliotecas, laboratórios e quadras de esportes".

Os autores citados fazem referência à ausência de espaço físico ou aos que existem, de pouca qualidade, como indicativo da não valorização social da disciplina de Educação Física. Shigunov (1997) em sua pesquisa avaliou as condições materiais para o ensino dessa disciplina, nas unidades escolares no município de Florianópolis, estado de Santa Catarina. Constatou diversas limitações nas escolas públicas relacionadas às condições materiais e às metodologias. Nesse sentido cabe a referência a Foucault (1987), cuja ideia do panoptismo (conceito para a compreensão da formação e do funcionamento das sociedades disciplinares ocidentais) não se materializou. Essa preocupação não foi preponderante na organização dos espaços da escola pública. Os indicativos apontam para a economia dos espaços, isto é, a relação custo-benefício, para abrigar um maior número de alunos, o investimento é em salas de aula.

Santin $(2002$, p. 68) chama a atenção para a desvalorização da educação física escolar por não ter um foco específico de estudo. Historicamente oscilou entre a higiene, a disciplina, o desempenho esportivo e a saúde.

A Educação Física escolar, certamente, pode perder esse estigma [...] e tornar-se uma ação pedagógica fundamental na formação do ser humano como um ser corporal [...] o corpo deve não ser mais um instrumento, mas a razão de viver. Ser corpo implica a idéia de viver e não de usar.

A inquietação que atinge os autores citados, nesse texto, também está expressa no texto dos diários do sujeito da investigação. A constituição de sua prática pedagógica cotidiana está restrita ao espaço físico, embora as diretrizes para o currículo da educação da infância, da última década, orientem o fazer dos educadores para as interações sociais por meio do desenvolvimento da linguagem (verbal e não verbal); da afetividade (emoções e sentimentos); da motricidade (movimentos, gestualidade e expansão do corpo) e da cognição (pensamento e dimensão racional). Esses pressupostos não aparecem como elementos centrais nas tentativas empreendidas no seu fazer docente. 
Há, também, diversas pesquisas que tratam do espaço e das possibilidades de reinventá-los, adequá-los aos interesses e necessidades dos educandos e dos professores, mas isso implica uma concepção de educação física, de currículo e de prática pedagógica. Espaços alternativos podem transformar-se em recursos inovadores e até (re)significarem o processo pedagógico.

Não se está defendendo, aqui, a manutenção da precariedade da infraestrutura das escolas, bem como do espaço físico das mesmas. A crítica apoia-se na ideia de que o trabalho pedagógico, somente, poderá desenvolver-se com qualidade se as condições materiais idealizadas estiverem postas, não só no caso da disciplina de educação física. Essa cultura deve ser rompida, pois contém inúmeros equívocos sobre a representação e apropriação do espaço escolar, o que está muito evidente no fragmento transcrito abaixo.

[...] me prestei a verificar o horário de utilização da quadra poliesportiva e descobri que o primeiro período estava vago. Meus olhos brilharam [...] A turma que mais precisa gastar energia é a primeira 1. Levei as crianças à quadra e inventei na hora a 'corrida das imitações'. Da maneira como eu corria, saltava ou pulava, elas tentavam fazer igual [...] A segunda turma, a B, saiu prejudicada, só consegui fazer o meu trabalho no espaço minúsculo do bicicletário (recorte do diário de 09/04/2009). Paradoxalmente dou a minha melhor aula do ano [...] eu consegui usar a quadra poliesportiva com as duas turmas. A brincadeira consistia em ir e voltar de uma distância pré-determinada [...] A turma gastando energia [...] todos, todos participando (recorte do diário de 27/04/2009).

Duckur (2004, p. 63) indica em seus estudos que é necessário "superar a ideia de que a ação educativa dos professores de educação física se dirige tão-somente à dimensão motora, ou melhor, a uma formação corporal desvinculada de outras dimensões", o que na prática implica na diversidade de espaços.

Na medida em que se corporifica o forte apelo ao espaço físico as formas de organização do tempo e do espaço pedagógico que se constituem de exigências e de possibilidades para a significação do currículo, ainda são pouco exploradas pelo que se infere na análise do conjunto dos diários investigados. Também há que se verificar qual tem sido o papel do administrador escolar ou gestor e do coordenador pedagógico ou supervisor (não importando, aqui, a denominação), no planejamento dos espaços, dos tempos e das atividades, na escola, para superar essa visão dicotômica. Neste caso nos textos dos diários, escritos pelo professor, não há menção ao acompanhamento da ação educativa, do currículo que a sustenta, bem como de sua operacionalização, isto é da elaboração e da execução do planejamento. Para superar uma prática focada na dimensão motora, desvinculada de outras dimensões que compõem a totalidade do ser humano, o esforço deve ser do coletivo escolar. 


\section{Saberes e fazeres do professor de Educação Física: o processo reflexivo do autor dos diários de classe}

Nóvoa (2007) esclarece que a reflexão sobre os saberes e fazeres dos docentes merece novos olhares. Aponta, como exemplo, os problemas e preocupações que estão no bojo das políticas governamentais, além da profissionalidade. Para o autor em tela, a década de 70 foi o tempo da racionalização do ensino, da pedagogia por objetivos, do esforço para prever, planificar e controlar. As reformas educativas nos anos 80 focaram a estrutura dos sistemas escolares e, especificamente, a engenharia do currículo. Em 90 a atenção voltou-se para as organizações escolares, o funcionamento, a administração e a gestão. Após esses ciclos, em virtude do relatório publicado pela $\mathrm{OCDE}^{6} \mathrm{em}$ 2005, as questões sobre a profissão docente ganharam visibilidade e, portanto, foram elencadas, mundialmente, como prioridade das políticas dos sistemas nacionais de educação. Emergem, ainda, nesse contexto, as pesquisas cujos temas obrigatórios tratam de reflexão e de intervenção no campo da educação.

No início do século XXI os professores, como em outros tempos, reaparecem como figuras centrais, porém, com outras tarefas. Não lhes cabe, apenas, a promoção do ensino e da aprendizagem, mas também o desenvolvimento de processos de integração e de práticas de inclusão social. A escola tornou-se o palco das pedagogias da alteridade, da polifonia, dos múltiplos sujeitos, dos múltiplos olhares, das múltiplas linguagens, das múltiplas representações. É o espaço da materialização de conflitos, de expectativas coletivas e individuais, da apropriação, criação, e recriação do conhecimento. Esse transbordamento torna a escola, obrigatoriamente, palco da reflexibilidade.

Então, partindo desses pressupostos, imaginário, espaço e as relações com a prática pedagógica, expressas pelo professor investigado, em seus diários, no terceiro conjunto, o propósito é reconstituir o processo reflexivo, do autor, em torno dos seus saberes e fazeres, como docente e, nessa perspectiva, discutir a prática pedagógica do professor de educação física.

Remetendo a Zabalza (2004, op. cit.) nos diários de aula, o professor expõe, explica, conta sobre o seu sistema de trabalho, o contexto da aula, descarrega tensões e interpreta sua ação diária o que de fato favorece, na recriação de situações narradas, o autoconhecimento e, como todo recurso autobiográfico, a reflexão, mediante o significado que o sujeito-autor dá às suas experiências.

$\mathrm{Na}$ ótica de Schön (1992), a prática profissional sustenta-se na competência para dialogar com os problemas reais, na reflexão em ação, na direção da reflexão sobre a ação. É o que o autor citado denomina de construção do problema, em oposição à resolução instrumental do problema. Este processo é compreendido como um prolongamento

\footnotetext{
$\overline{6}$ Organização para a Cooperação e Desenvolvimento Econômico, criada em 30 de setembro de 1961, sucedendo à Organização para a Cooperação Econômica Europeia, criada em 16 de abril de 1948.
} 
do processo de construção de saberes e fazeres da profissão. Na análise dos textos, mediante a trajetória das práticas cotidianas, cujos pontos articulam esse diálogo com as situações descritas, esse professor identifica as deficiências na formação, avalia os seus procedimentos didáticos e reflete sobre a sua condição profissional e humana.

[...] ter que optar por trabalhar com as séries iniciais [...] um terreno muito diferente no qual eu me realizo dando aula [...]. O meu vínculo é com as séries finais onde desempenhei um ótimo e reconhecido trabalho [...]. Cheguei à escola sem saber o que fazer com as crianças [...] ficava me perguntando durante as aulas, o que eu estava fazendo ali? Foi uma droga de aula. (Recorte do diário do dia 09/03/2009.)

Considerando as percepções a respeito do seu desempenho no processo ensino-aprendizagem o foco principal, da narrativa, a essa altura, concentra-se na organização e no funcionamento da disciplina de educação física, na escola. E, além disso, diz respeito ao pensamento crítico-reflexivo sobre as conexões entre o imaginário e os saberes construídos, no ambiente da escola, ao longo do processo de sua atuação, com alunos maiores. A perplexidade, a indignação e a insegurança representam, nessa circunstância, um comportamento que pode ser elucidado por Bourdieu (1972, apud ORTIZ, 1983, p. 15), quando se refere à efetivação de práticas exercidas social e coletivamente que configuram um habitus $^{7}$. A estrutura lógica desta configuração está no âmbito da subjetividade das ações e, na noção de experiência, substância que a configura. Assim, no processo reflexivo, faz-se necessário identificar e compreender os fundamentos da prática para confrontá-los com as situações que emergem no contexto, e como diz Contreras (1997), expressar as formas pelas quais se busca respostas singulares dentro de situações concretas e complexas. Neste exercício, evidencia-se a intencionalidade do professor expressa no esforço de planejar as atividades.

Resolvi inventar uma aula com balões [...] uma aula diferente, mas logo vi que se tornaria complicado no dia de hoje [...] levei-os para a rua e sequer havia reparado nas condições climáticas. O resultado foi uma choradeira [...]. A primeira turma me fez enxergar o quanto inexperiente estou. Sobre as atividades consegui concluir apenas parte das mesmas. (Recorte do diário do dia16/03/2009.) Por sugestão de uma colega [...] trabalhei com uma técnica de desenvolvimento da lateralidade, primeiro em sala de aula [...]. A atividade de sala foi iniciada com uma música. Depois eles foram divididos em duplas, após iam caminhando ao som do apito [...] Apesar de ter me achado de fraca atuação, minha capacidade de improviso estava voltando. (Recorte do diário do dia 23/03/2009.)

\footnotetext{
7 Este conceito foi construído a partir de pesquisas realizadas na Argélia entre camponeses da região francesa de Béarn entre 1950 e 1960 por Bourdieu $(1963,1972)$, observando a situação de desamparo de indivíduos arrancados de um universo rural e submetidos a um ambiente urbano e capitalista. Para Bourdieu (1972, p. 101), "habitus é uma subjetividade socializada [...] deve ser visto como um conjunto de esquemas de percepção, apropriação e ação que é experimentado e posto em prática, tendo em vista que as conjunturas de um campo o estimulam”.
} 
Ao valorizar a experiência gerada pela prática tomou a decisão de exercitar a sua criatividade e de buscar ajuda. Porém, como não desenvolveu uma reflexão apoiada em um referencial teórico que contribuísse para iluminar tal decisão, a resposta não resultou no que ele esperava. Nesse caso as epistemologias construídas sobre a infância.

Zabala (1999, p. 15) afirma que "a decisão de adotar uma estratégia de mudança, precede o desenvolvimento da compreensão. A ação inicia a reflexão". Nesse sentido, as opções desvinculadas de referenciais que auxiliam na interpretação dos saberes e dos fazeres em qualquer profissão são, na maioria, desastrosas.

Ainda, na ótica de Zabala (1999, op. cit.), a capacidade para interpretar um fato, ou a debilidade epistemológica não é inerente à profissão docente, decorre de um modelo profissional constituído historicamente. Acrescenta, ainda, que o processo educativo é complexo, encerra muitas variáveis, o que torna mais difícil a análise e, consequentemente, a reflexão. Os estudos sobre fazeres e saberes docentes contemplam uma visão processual da prática pedagógica, o que remete aos marcos teóricos e conceituais, às formas de intervenção, à identidade e ao perfil profissional, entre outros.

Tardif (2002) realizou uma pesquisa empírica com professores, tratando da relação teórico-prática e a natureza dos saberes que são mobilizados e utilizados por eles em seu trabalho diário. Conclui que o saber não se reduz a processos cognitivos. Um saber é construído na interface entre o individual e o social. E os saberes que têm como objeto, de trabalho, seres humanos é plural e temporal. Advém de várias instâncias: da família, da escola, da cultura pessoal, dos pares, dos cursos de formação e do decurso da carreira. Os professores, ao refletirem sobre a prática, revisitam o processo que os constituiu professores, as representações sobre a profissão, significados e sentidos de seu papel. Isto é, os aspectos subjetivos ligados à experiência, à trajetória pré-profissional e profissional e contextos de trabalho. Entretanto estes saberes podem permanecer adormecidos, para os docentes, se as formas de construção não forem reveladas, vividas, interpretadas e compreendidas. Ao realizar esse exercício, mediante o registro, torna-se possível articular estes saberes.

Nesse ponto cabe, novamente, a interlocução com Zabalza (2004, op. cit) quando escreve sobre a validade da prática da pesquisa, com professores a partir dos diários de classe. O envolvimento do professor, no registro de sua prática, é multidimensional. Além do caráter longitudinal, é histórico. Os diários refletem as reconstruções de períodos vitais, isto é, a sequência, a evolução e a atualidade.

Isto posto, cabe tratar da prática pedagógica do professor de educação física, considerando que a representação não está dissociada da apropriação, como explica Chartier (1990, op. cit.) referindo-se à forma de atuação, própria dos sujeitos, atores sociais, onde estão inseridos, o que legitima e/ou justifica enfrentamentos, escolhas e condutas.

No caso em estudo evidencia-se o enraizamento de um conjunto de práticas culturais em torno de práticas corporais que foram apropriadas, tecidas e vivenciadas pelo professor, enquanto saber, como revelam os indícios registrados pelo autor dos diários. 
Não tive vergonha de reproduzir o que os meus primeiros professores de educação física fizeram. Dividi o espaço [...] e larguei a bola. (Recorte do diário do dia 27/04/2009.)

A referência à apropriação das práticas culturais, traduzida na reprodução consciente de uma conduta que, contraditoriamente, é negada, traz o espaço como referência imperativa para o seu fazer docente. É o espaço que produz sentido e dá inteligibilidade à sua prática pedagógica. O recorte que segue confirma a inferência.

Consegui arrumar meus horários em definitivo [...] uma troca que aos olhos dos outros pode parecer loucura. Troquei por uma escola na zona rural. O local é um paraíso, salas amplas, três quadras [...]. (Recorte do diário do dia 04/05/2009.)

A opção do professor investigado demonstra que, como de certa forma já foi anunciado, não se articula em torno de um saber pedagógico, mas da configuração do espaço, da possibilidade de usufruir e atuar em um espaço físico que lhe garanta o seu lugar específico na escola. O seu discurso justifica, simbolicamente, a dimensão espacial da atividade educativa, na disciplina de educação física. É no espaço físico que se edificam seus saberes profissionais, mas não retratam os conhecimentos teóricos e metodológicos específicos da educação física escolar. Esta postura representa, também, uma forma silenciosa de ensino e de aprendizagem.

Estudos sobre a educação e, especificamente sobre a educação física escolar, desenvolvidos, também, a partir de 1990, apontam diferentes concepções e tendências quanto às práticas pedagógicas curriculares. No Brasil, destaca-se Ghiraldelli, com a obra Educação física progressista: a pedagogia crítico-social dos conteúdos e a educação física brasileira, publicada em 1991. José Carlos Libâneo ${ }^{8}$, que escreve o prefácio da obra, manifesta que o momento desta publicação era muito oportuno haja vista o conteúdo crítico-reflexivo que trazia em seu bojo sobre os fundamentos teóricos e metodológicos da disciplina, reconhecendo a importância de articular a prática da educação física escolar às exigências históricas e sociais de um determinado contexto e às especificidades pedagógicas.

\footnotetext{
8 Professor, graduado Filosofia pela Pontifícia Universidade Católica de São Paulo (1966), mestrado em Filosofia da Educação (1984) e doutorado em Filosofia e História da Educação pela Pontifícia Universidade Católica de São Paulo (1990). Pós-doutorado pela Universidade de Valladolid, Espanha (2005). Professor Titular aposentado da Universidade Federal de Goiás. Atualmente, é pprofessor ttitular da Universidade Católica de Goiás, atuando no Programa de Pós-Graduação em Educação, na Linha de Pesquisa Teorias da Educação e Processos Pedagógicos. Coordena o Grupo de Pesquisa do CNPq: Teorias e Processos Educacionais.
} 
Outras publicações mais recentes como as de $\operatorname{Vago}^{9}$ (2001-2010) que discutem os caminhos para a educação física escolar ensejam a atuação refletida do docente quanto aos espaços, os conceitos, os conteúdos, os métodos, enfim, quanto ao significado do processo de ensino e de aprendizagem. Consideram, ainda, que os docentes não devem permanecer à margem dos processos pedagógicos, como se a educação física, enquanto disciplina, não tivesse finalidade em seu ensino e por isso não fosse necessário planificar uma proposta de intervenção, no cotidiano escolar, criar as condições favoráveis para a sua realização e, consequentemente, para a sua aprendizagem.

É ponto de ancoragem, para a reflexão, a compreensão dos saberes que estão na base da formação para o ensino da educação física escolar, aqueles que se traduzem em propostas de intervenção, de acordo com o contexto da ação docente e, os demais saberes, os saberes da profissão docente construídos, desconstruídos e reconstruídos na trajetória da carreira, no campo de trabalho.

Estes aspectos descritos acima não se tornaram evidentes nos textos dos diários de classe, como elementos importantes para o processo de reflexão. Infere-se, nas entrelinhas, que a concepção de educação física escolar, para o professor pesquisado, é sustentada no âmbito das práticas corporais, mediatizadas na realização de atividades.

No entendimento de Freitas (2007), os estudos do campo da educação e os estudos pedagógicos foram secundarizados na formação dos professores, rebaixando as exigências do campo da teoria pedagógica na organização curricular, descaracterizando o ensino como atividade essencial. O resultado é a baixa qualidade da formação teórica, no campo das Ciências da Educação e no campo das áreas específicas, na medida em que se priva da ciência a formação dos professores. Assim, ao contrário de promover a profissionalização dos professores, preconizada nos discursos, o que se favorece é sua desprofissionalização, uma vez que a formação docente estaria sendo transferida para o campo da epistemologia da prática ${ }^{10}$.

9 Professor titular do Departamento de Educação Física da Escola de Educação Física, Fisioterapia e Terapia Ocupacional da Universidade Federal de Minas Gerais. Professor do Programa de Pós-graduação "Conhecimento e Inclusão Social”, da Faculdade de Educação da UFMG. Possui Licenciatura em Educação Física pela UFMG (1983), mestrado em Educação pela UFMG (1993) e doutorado em História da Educação pela USP (1999). Em 2009, Estágio Pós-doutoral no Centro de Pesquisa e Documentação em História Contemporânea do Brasil (CPDOC), da Fundação Getúlio Vargas, com bolsa Pós-Doutorado Sênior (PDS), do CNPq. Membro do CEMEF - Centro de Memória da Educação Física da UFMG. Pesquisador do GEPHE - Grupo de Estudos e Pesquisas em História da Educação, da Faculdade de Educação da UFMG.

10 Tardif (2000) conceitua por epistemologia da prática o estudo dos saberes cotidianos, do senso comum, dos jogos de linguagem e dos sistemas de ação por meio dos quais a realidade social e individual é constituída. Como os profissionais, incorporam esses saberes, os produzem, os utilizam, os aplicam e os transformam em função dos limites e dos recursos inerentes às suas atividades de trabalho, como também, a natureza desses saberes, assim como o papel que desempenham tanto no processo de trabalho docente quanto em relação à identidade profissional dos professores.

Educação Por Escrito, Porto Alegre, v. 5, n. 1, p. 111-128, jan.-jun. 2014 
No caso, em estudo, haja vista todo o processo de interlocução mediada, isto é, o diálogo com o escrito desvelase que, sem o referencial necessário para vencer as vicissitudes da profissão e de um contexto escolar adverso, o professor, autor dos diários de classe, decidiu transferir-se para outra instituição. Esta decisão explicita que é no espaço físico escolar, no seu imaginário, apropriado para a prática da educação física, que ele encontra sentido e significado para o exercício da docência qualificando, dessa forma, a sua prática pedagógica.

\section{O percurso metodológico}

Mazzotti (1998), afirma que o planejamento de estudos qualitativos não é tarefa fácil porque ao contrário das pesquisas quantitativas, as investigações qualitativas, por sua diversidade e flexibilidade, diferem bastante quanto ao grau de estruturação prévia com relação aos aspectos a serem definidos em um projeto de pesquisa.

Assim, na abordagem qualitativa, conforme Lincoln e Guba (1985, apud MERRIAM 1998), o foco e o "design"11 não podem ser definidos a priori, emergem, por um processo de indução, do conhecimento do contexto, das múltiplas dimensões da realidade e da influência dos seus atores.

Esta foi a proposta. No horizonte da pesquisa qualitativa, constituir um caminho, para investigar os saberes e fazeres docentes a partir dos textos de oito diários de aula escritos por um professor de educação física, de uma instituição educativa da rede pública, do município de Porto Alegre (RS) que, voluntariamente, participou da pesquisa e se dispôs a escrevê-los como exercício de reflexão sobre sua prática pedagógica, durante o período compreendido entre os meses de março a junho do ano de 2009.

Na ótica de Minayo (2004) por se tratar de material autobiográfico, o estudo caracteriza-se como um estudo de caso único, na perspectiva de que o documento (diários de classe) é revelador da dinâmica da atividade de apenas um sujeito. No caso específico, o sujeito estudado é considerado representativo entre o grupo de professores de educação física escolar.

Pela natureza do material situar-se no plano discursivo e os dados comunicados pela linguagem escrita, adotouse os procedimentos da análise de conteúdo. Os textos dos diários foram analisados com base no referencial construído por Bardin (2002), na tentativa de encontrar expressões e/ou unidades de sentido desveladoras dos saberes e fazeres docentes. Pela forma processual com que os dados foram tratados, para se efetivar a análise e interpretação dos resultados, três etapas foram consideradas básicas no processo de análise e interpretação dos textos dos diários:

$\overline{{ }^{11} \text { Design, significa o }}$ desenho, o delineamento do processo de pesquisa. 
a) $\mathrm{Na}$ primeira etapa foi realizada a pré-análise, isto é, a leitura e análise textual para definir as unidades de conteúdo (registro e contexto).

b) Na segunda etapa, operou-se com os processos de codificação, mediante a organização de um quadro, reunindo as unidades de sentido, tendo como critério a preponderância da ocorrência; a classificação, resultante do agrupamento das unidades de sentido, adotando-se os critérios de inclusão e exclusão, o que representou a produção de sínteses coincidentes e, ou divergentes; a categorização dos dados, cujo processo, à medida que se efetuava a análise iam se constituindo e emergindo as categorias, bem como, os elementos de análise. O critério adotado para a constituição das categorias foi o da identificação de conceitos expressos pelas unidades de sentido.

c) Na terceira etapa, fez-se a interpretação inferencial, na tentativa de desvendar o conteúdo subjacente ao que foi manifesto, mensagens implícitas e, ou silenciadas. Como observam aqueles que se dedicam a estudos qualitativos, a pesquisa qualitativa pode ser comparada a um trabalho de artesão. À medida que a pesquisa avança, o pesquisador vai construindo o caminho como se fosse tecendo, com o fio dos achados, o resultado do seu trabalho. Desse modo, do diálogo com o escrito, emergiram as categorias organizadas em três conjuntos assim constituídos: imaginário e espaço; espaço e prática pedagógica; saberes e fazeres do professor de educação física.

Tendo como fio condutor a questão que focava o significado espaço físico, para o professor de educação física investigado, como um indicador de qualidade para a sua prática pedagógica, buscou-se na literatura pertinente, as possibilidades de interlocução para a composição do texto fundamentador, que deu suporte à interpretação dos textos dos diários, sobre o significado do espaço físico escolar para o professor de educação física e a relação, desse espaço, com o seu exercício de docência.

A análise, a interpretação e a interlocução mediadas, pela devida fundamentação teórica, constituiu o processo de investigação, coerente com o posicionamento de Tardif (2000, p. 11):

o trabalho não é [...] um objeto que se olha, mas uma atividade que se faz, e é realizando-a que os saberes são mobilizados e construídos. Esse enfoque considera que o profissional, sua prática e seus saberes não são entidades separadas, mas "copertencem" a uma situação de trabalho na qual "coevoluem" e se transformam. Querer estudar os saberes profissionais sem associá-los a uma situação de ensino, a práticas de ensino e a um professor seria, então, um absurdo. É a mesma coisa que querer estudar uma situação real de trabalho, uma situação real de ensino, sem levar em consideração a atividade do professor e os saberes por ele mobilizados (grifos do autor). 


\section{Considerações finais}

Por menor que seja a representatividade de um sujeito, em relação ao conjunto, no caso, os professores de educação física escolar, o importante, nesse exercício de buscar a interlocução entre os diários de aula e a escrita acadêmica, foi muito significativo pela exemplaridade, pela possibilidade de apreender as relações entre o que estava evidente, nos textos e, especialmente, por desvelar o que se encontrava latente por entre as linhas: concepções, crenças, valores, sentimentos, episódios e dilemas.

Dentre as técnicas e instrumentos de coleta de dados, na abordagem qualitativa, o diário de classe foi visto como um recurso que expressa a inteireza do sujeito investigado. As vivências e experiências, que podem perder o seu vigor no decorrer do processo, no contexto da pesquisa, se escritas, materializam-se e, ao tornarem-se concretas, permanecem à disposição para, de distintas perspectivas, serem interpretadas e esclarecidas.

A aceitação do professor, em escrever os diários e participar da pesquisa, indica um gesto de coragem. Ele, conscientemente, desnudou-se, produzindo os acontecimentos. E a continuidade é a possibilidade que o próprio diário oferece. Pesquisadores interessados, neste material, poderão explorar outros dados dos relatos e dar-lhes tratamentos distintos, haja vista o grande espectro de enfoques e, também, porque em termos documentais, os escritos do diário de classe representam a realidade em processo.

Em relação à investigação, pela natureza do estudo e pelas condições muito particulares da produção dos dados, o processo de análise e interpretação não está esgotado e seria, de certo modo, arriscada a pretensão de considerá-lo finalizado. Justifica-se a continuidade pela riqueza de dados não explorados, as omissões involuntárias e, como em toda pesquisa de cunho qualitativo, o olhar do pesquisador sobre o fenômeno que lhe interessa.

Outra limitação, embora se considere as evidências significativas e a veracidade das informações, o conteúdo da análise e da interpretação ficou restrito aos textos dos diários, aos significados dos recortes feitos em face da intencionalidade de investigar sobre o significado do espaço físico escolar para o professor de educação física e a relação, desse espaço, com o seu exercício de docência.

Outros olhares, com certeza, poderão trazer à tona novos indícios e, dessa forma, aprofundar as relações entre imaginário, espaço e prática pedagógica, propiciando ao público leitor as suas próprias análises e interpretações sobre os saberes e fazeres de um professor de educação física escolar.

\section{Referências}

ANASTASIOU, Léa das Graças. Processos de ensinagem na universidade. Joinville: Ed. UNIVILLE, 2006.

BARDIN, Laurence. Análise de conteúdo. Trad. Luís Antero Reto e Augusto Pinheiro. Lisboa: Edições 70, 2002. 
CASTORIADIS, Cornelius. A instituição imaginária da sociedade. Rio de Janeiro: Paz e Terra, 1982.

CHARTIER, R. A história cultural entre práticas e representações. Lisboa: Difel, 1990.

CERTEAU, M. A invenção do cotidiano. Petrópolis: Vozes, 2001.

CONTRERAS, Domingo José. La autonomía del profesorado. Madrid: Ediciones Morata, 1997.

DUCKUR, Lusirene Costa Bezerra. Em busca da formação de indivíduos autônomos nas aulas de educação física. São Paulo, Campinas: Autores Associados, 2004.

DURAND, G. As estruturas antropológicas do imaginário. São Paulo: Martins Fontes, 1997.

GHIRALDELLI, Paulo. Educação física progressista: a pedagogia crítico-social dos conteúdos e a educação física brasileira. São Paulo: Edições Loyola, 1991.

HERNÁNDEZ, F. El relato biográfico em sociologia. Revista Internacional de Sociología, v. 44, n. 3, p. $227-294$, 1986.

HORN, Maria da Graça Souza. Sabores, cores, sons, aromas: a organização dos espaços na educação infantil. Porto Alegre: Artmed, 2004.

LARROSA, J. Notas sobre a experiência e o saber de experiência. In: Revista Brasileira de Educação, n. 19, jan.-abr. 2002.

MINAYO, Maria Cecília de Souza. O desafio do conhecimento: pesquisa qualitativa em saúde. São Paulo: Hucitec, 2004.

NÓVOA. António. Desenvolvimento profissional de professores para a qualidade e para a equidade da aprendizagem ao longo da vida. In: O REGRESSO DOS PROFESSORES - conferência Presidência Portuguesa do Conselho da União Europeia. Lisboa, Parque das Nações, Pavilhão Atlântico, Sala Nónio 27 e 28 de setembro de 2007.

ORTIZ, Renato (Org.). Pierre Bourdieu. São Paulo: Ática, 1983. (Coleção Grandes Cientistas Sociais).

RODRIGUES, S. B. P. Espaço escolar e cidadania excluída. Rio de Janeiro, Revan, 2003.

SÁ, C. P. de.; ARRUDA, A. O estudo das Representações Sociais no Brasil. In: Revista de Ciências Humanas, Florianópolis: EDUFSC, ed. esp. temática, p. 11-31, 2000.

SANTIN, S. Textos malditos. Porto Alegre: EST. Edições, 2002.

SEVERINO, A. de J. A escola e a construção da cidadania. In: MARTINS, J. de S. et al. Sociedade civil. São Paulo: Papirus, 1992.

SHIGUNOV, V. A influência dos espaços físicos e materiais esportivos das escolas públicas no desempenho do professor de educação física. In: Anais do X COMBRACE, Goiânia, v. I, p. 679-686, 1997.

SCHÖN, Donald. La formación de profesionales reflexivos. Hacia un nuevo diseño de la enseñanza y el aprendizaje en las profesiones. Barcelona: Paidós, 1992.

SOUZA LIMA, M. W. Espaços Educativos: usos e construções. Brasília, MEC, 1998.

TARDIF, Maurice. Saberes docentes e formação profissional. Petrópolis: Vozes, 2002. 
TARDIF, Maurice. Saberes profissionais dos professores e conhecimentos universitários. Elementos para uma epistemologia da prática profissional dos professores e suas consequências em relação à formação para o magistério. In: Revista Brasileira da Educação, n. 13, jan.-abr, 2000, n 13.

VAGO, T. M. Cultura escolar cultivo de corpos: Educação Physica e Gymnastica como práticas constitutivas dos corpos de crianças no ensino público primário de Belo Horizonte (1906-1920). Bragança Paulista: EDUSF, 2002.

VIÑAO, Antonio. Espaços, usos e funções; a localização e disposição física da direção escolar na escola graduada. In: BENCOSTTA, Maucus Levy (Org.). História da educação, arquitetura e espaço escolar. São Paulo: Cortez, 2005.

ZABALA, Antoni. Como trabalhar os conteúdos procedimentais em aula. Porto Alegre: Artmed, 1999.

ZABALZA, Miguel A. Diários de aula. Porto Alegre: Artmed, 2004.

\section{Endereço para correspondência:}

Jordelina Beatriz Anacleto Voos

Rua Gertrudes Benta Costa, 60 - Bairro Atiradores

89203215 Joinville, SC, Brasil

E-mail: <jordelina.voos@acad.pucrs.br>

Recebido em: abril/2014

Aceito em: maio/2014 